\title{
Maintenance of livestock farming may buffer population decline of the Barn Swallow Hirundo rustica
}

\author{
ROBERTO AMBROSINI, DIEGO RUBOLINI, PAOLA TROVÒ, \\ GIOVANNI LIBERINI, MARCO BANDINI, ANDREA ROMANO, \\ BEATRICE SICURELLA, CHIARA SCANDOLARA, \\ MARIA ROMANO and NICOLA SAINO
}

\section{Summary}

Populations of farmland and long-distance migratory birds have suffered steep, often dramatic, declines in the last few decades. The Barn Swallow Hirundo rustica is a small migratory farmland bird that breeds synanthropically in farms, particularly where livestock is reared. Populations of this species have suffered marked declines in different parts of its European breeding range. Here, we first report a dramatic decline of $8.4 \%$ per year of the number of breeding pairs and the extinction of $19.6 \%$ of the colonies in three agricultural areas in Northern Italy, which differ in general ecological conditions. This decline was estimated on a very large sample of 190 randomly chosen farms where breeding pairs were censused both in 2001 and 2010, and occurred at different rates in the three study areas. Barn Swallows declined most (9.3\% per year) in an intensively cultivated area where colonies are widespread, and least (1.3\% per year) in a hilly area with a comparatively small density of colonies. Variation in livestock farming significantly influenced population dynamics. Specifically, cessation of livestock farming at a given farm between the two census years resulted in a significantly steeper decline in the number of breeding pairs compared to farms where livestock farming was maintained. Our findings highlight the fact that European populations of Barn Swallows breeding in intensively cultivated agro-ecosystems may become significantly depleted in the next decades, and indicate that maintenance of livestock farming may contribute to buffering the population decline of this species.

\section{Introduction}

The populations of several bird species breeding in Europe have undergone marked, mostly negative, demographic changes during recent decades (Tucker and Heath 1994, BirdLife International 2004, Donald et al. 2006). The sign and steepness of these trends, however, are distributed non-randomly among taxa and according to species' ecology and life-histories, as susceptibility to decline is associated with specific habitat preferences and major life-history traits such as e.g. migratory behaviour (Sanderson et al. 2006, Møller et al. 2008, Both et al. 2010).

Birds breeding in farmland have suffered steeper declines than forest or aquatic species, partly because of the direct impact of the changes in agricultural practices that took place in the course of the second half of the twentieth century. These changes have resulted in a rapid shift from the traditional agricultural mosaic that characterised farmland habitats for centuries, to large-scale, homogeneous, intensively cultivated agro-ecosystems with low biodiversity (Chamberlain et al. 2000, Chamberlain and Fuller 2001, Donald et al. 2001, 2006). For example, it has been shown that population trends of farmland birds negatively covaried with cereal yield across European countries 
(Donald et al. 2001), suggesting that agricultural intensification, determining large-scale shifts in land management, may be causally related to farmland bird declines (Chamberlain et al. 2000).

Long-distance trans-Saharan migratory birds have declined more than short-distance migrants and residents (Sanderson et al. 2006, Møller et al. 2008, Both et al. 2010). This can have several concomitant causes. The varying rate of change in ecological conditions occurring in the areas where birds spend different parts of their annual life cycle may result in an ecological mismatch of species that are not able to track the optimal conditions for reproduction under a changing climate (Both and Visser 2001, Both et al. 2006, Ambrosini et al. 2011, Saino et al. 2011). Rapid changes in the ecological conditions of African wintering or stopover habitats may also negatively affect migrant survival and population trends (Sanderson et al. 2006, Zwarts et al. 2009). In particular, it has been observed that most declining species winter in open-dry habitats in Africa (Sanderson et al. 2006), probably due to increasing habitat degradation and loss within African drylands, such as the Sahel region, a major wintering and staging area for Afro-Palearctic migrants (Zwarts et al. 2009).

The Barn Swallow Hirundo rustica epitomises some of the risk factors that have been shown to predict demographic decline in comparative studies. It is a long-distance migrant that overwinters in open habitats south of the Sahara Desert (Cramp 1988, Møller 1994, Turner 2006). It is also a farmland bird, foraging mainly on open hayfields and pastures, and along hedgerows. In addition, it is strictly associated with traditional rural buildings for nesting. In fact, since breeding takes place most often in cowsheds and stables with cattle and horses, it can be markedly affected by rapid changes in livestock farming practices that have occurred widely in Europe during recent decades, resulting in the progressive abandonment of traditional cattle sheds in favour of modern, intensive sheds that are less suitable for Barn Swallow nesting (Møller 1994, 2001, Ambrosini et al. 2002, Turner 2006).

Barn Swallows breeding in farms where livestock is reared have larger reproductive success than those breeding in farms without it (Grüebler et al. 2010). This probably occurred because Barn Swallows benefit from warmer indoor temperatures when they nest in buildings with livestock (Ambrosini and Saino 2010). Warmer temperatures in turn allow for earlier reproduction and a larger number of pairs laying a second clutch (Grüebler et al. 2010). In addition, presence of livestock at a farm is usually correlated with higher food availability for the insectivorous Barn Swallow, both because manure enhances insect production, and because hayfields and pastures, which are the preferred foraging habitat of this species, are larger around farms with livestock (Møller 2001, Ambrosini et al. 2002, Evans et al. 2007, Grüebler et al. 2010). All these benefits result in an overall larger nestling survival rate in farms with livestock, particularly of second broods (Grüebler et al. 2010), and may explain the strong preference of nesting Barn Swallows for cowsheds, stables and, in general, for buildings where livestock is reared (Ambrosini and Saino 2010, Grüebler et al. 2010). Cessation of livestock farming at a farm may therefore result in lower reproductive success (Grüebler et al. 2010) and fewer yearlings recruited to the colony (Møller 2001).

The Barn Swallow has declined in several parts of its European range, but the extent of this decline varies widely across geographical areas (Møller 1989, Tucker and Heath 1994, Siriwardena et al. 1998, Robinson et al. 2003, BirdLife International 2004, PECBMS 2009). Several mechanisms operating in different parts of the annual life-cycle, and thus in different geographical regions, have been invoked as causes of the decline. Agricultural intensification and cessation of livestock farming at a farm may determine the decline of the local colony (Møller 2001, Ambrosini et al. 2002), whereas habitat degradation and loss on breeding and wintering grounds, or along migration routes probably act synergistically to determine the general decline of Barn Swallow populations (Saino et al. 2004, Robinson et al. 2008).

In the present study, we first report on the population dynamics of Barn Swallows breeding in three agricultural areas in northern Italy, which differ in general ecological conditions, such as altitude, major land use, and farming intensity, based on a very large sample of 190 farms where breeding pairs have been censused both in 2001 and 2010 . Then, we analyse the effect of animal farming on local population trends to test the prediction that cessation of animal farming during the study period resulted in more negative population trends compared to conditions where 
animal farming did not change (i.e. it was present or absent both at the start and the end of the study period). By comparing population changes taking place at each of the three study areas, we could also explore whether the effects of animal farming differed according to general ecological conditions of the area where colonies were located.

\section{Methods}

\section{Study areas and field methods}

The study was carried out in Northern Italy, specifically in the Parco Regionale Adda Sud ('AS' hereafter; coordinates of the approximate centre: $45^{\circ} 19^{\prime} \mathrm{N}, 9^{\circ} 40^{\prime} \mathrm{E}, 24.260 \mathrm{ha}$ ), in the Parco Piemontese della Valle del Ticino (' $\mathrm{TP}^{\prime}, 45^{\circ} 33^{\prime} \mathrm{N}, 8^{\circ} 44^{\prime} \mathrm{E}, 6.56 \mathrm{I}$ ha), and in the Parco Regionale di Montevecchia e della Valle del Curone ('MC', $45^{\circ} 42^{\prime} \mathrm{N}, 9^{\circ} 22^{\prime} \mathrm{E}, 2.350$ ha) (Figure 1). Maize fields $(44 \%)$ and hayfields $(32 \%)$, i.e. fields where grass or alfalfa Medicago sativa are not grazed but cut to produce dry feed for livestock during the winter, are the prevalent crop types in AS, which is located in the low Po Plain of Lombardy (height of monitored farms: 40-108 m asl). Woods $(37 \%)$ and hayfields $(25 \%)$ prevail in TP, which is in the high Po Plain in Piedmont (height of monitored farms: 99-281 $\mathrm{m}$ a.s.l.). $\mathrm{MC}$ is a hilly area (height of monitored farms: $258-442 \mathrm{~m}$ ) in Lombardy where coppices (38\%) and hayfields $(24 \%)$ are the predominant land uses.

The size of farms, as estimated during the 2010 census and expressed as the overall area of cowsheds, stables, barns and other buildings that are accessible to Barn Swallows at each farm (see below for a definition of 'farm'), was much larger in AS (on average 3,053.3 $\pm 288.5 \mathrm{SE} \mathrm{m}{ }^{2}$,

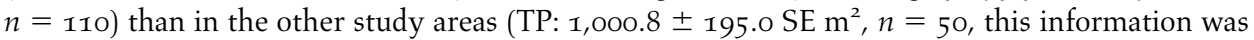
unavailable for 6 farms; MC: $238.1 \pm 45.5 \mathrm{SE} \mathrm{m}^{2}, n=49$, all farms censused in 2010 were included in this analysis). Conversely, farm density is larger in MC ( 3.4 farms km$~^{-2}$, total number of farms in the study area: $\mathrm{n}=80$ ) than in AS (1.3 farms $\left.\mathrm{km}^{-2}, \mathrm{n}=319\right)$ or in TP (1.2 farms $\mathrm{km}^{-2}, \mathrm{n}=76$ ), total number of farms in the study area: $\mathrm{n}=80$ ), as estimated by a complete census of all farms at each study area performed by means of detailed maps (scale 1:10,000), aerial photos, and Google Earth (Mountain View, CA).

As sample units we used groups of rural buildings (hereafter 'farms') that were separated by at least $100 \mathrm{~m}$ from other groups of buildings (Ambrosini et al. 2002). Albeit most buildings were originally farms, their use at the time of the censuses could have changed to e.g. houses, restaurants, or farm holiday centres. In AS, a long-term monitoring project of Barn Swallow populations is ongoing since 1999 in a random sample of the farms in the Park or in the surrounding area (see Ambrosini et al. 2002 for details). In this study area, 108 farms were monitored both in 2001 and 2010 and 94 in all years in 1999-2010. In TP, 56 farms within the boundaries of the Park or in the surrounding area were monitored both in 2001 and 2010 . The other farms in this study area could not be censused due to inaccessibility or unwillingness of the owners. For the same reasons, in 2010 we could not obtain reliable estimates of colony size at three farms in TP (though we could confirm that breeding took place). These farms were therefore excluded from the analyses of demographic trends and colony size, but not from those of colony extinction probability. In MC, 26 randomly chosen farms were monitored both in 2001 and 2010.

In 2010 all farms at each study area were monitored according to a standardised protocol reported in detail in Ambrosini et al. (2002). Briefly, each farm was visited every 14 days and the content of all nests inspected. The number of pairs at a farm was then estimated as the maximum number of nests simultaneously active (i.e. with eggs or nestlings) during April-June. In 2001 farms in AS were monitored according to the same protocol as above, while farms in TP and in MC were visited monthly and all nests inspected. Colony size was estimated as above.

Data on the presence of livestock at each farm were collected during visits to the farms in each year in AS. In TP and in MC livestock data for 2010 were collected during the visits to the farms, while those for 2001 were obtained by interviewing the farmers (Ambrosini et al. 2002). This information was summarised as a dichotomous variable ('livestock farming') accounting for 

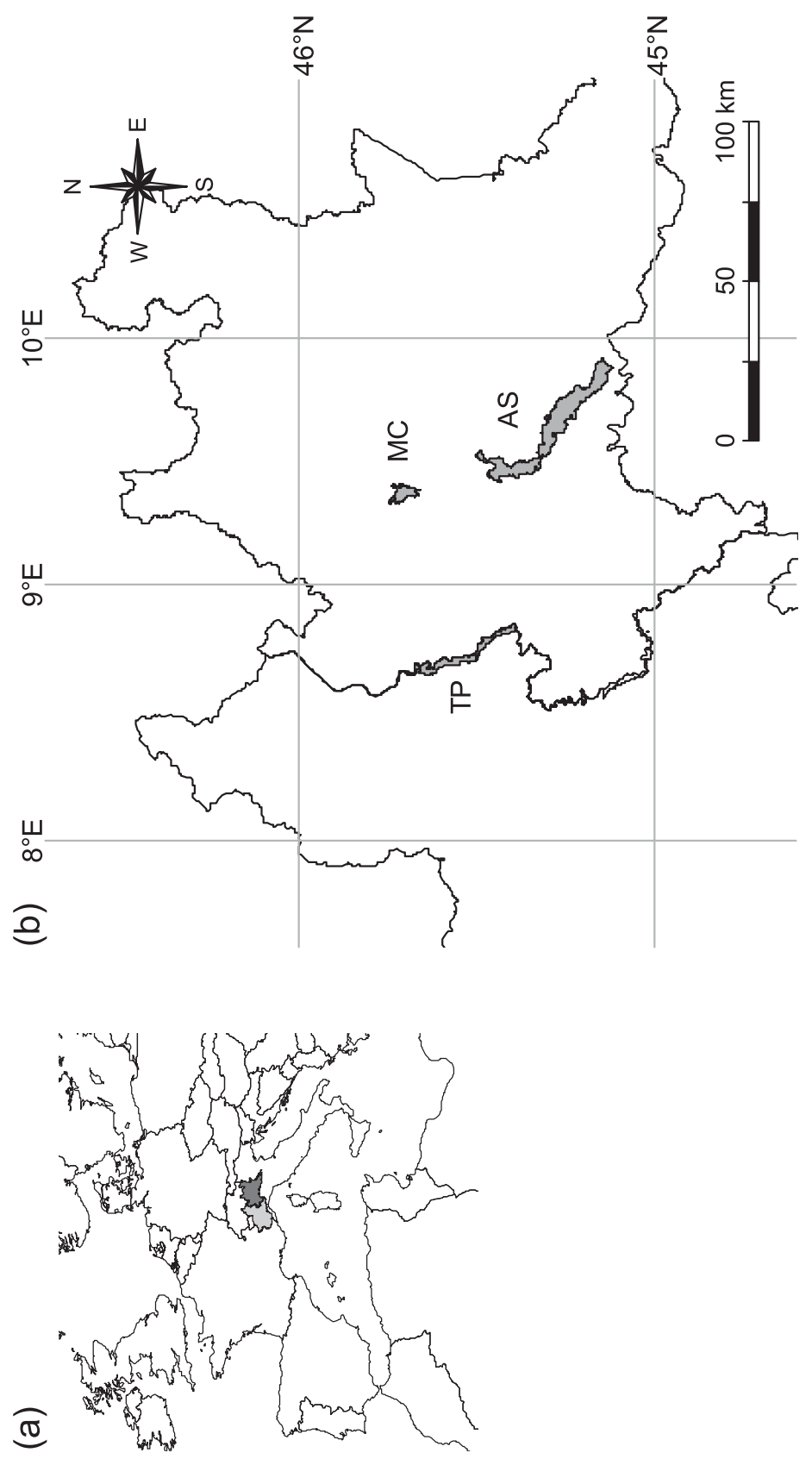

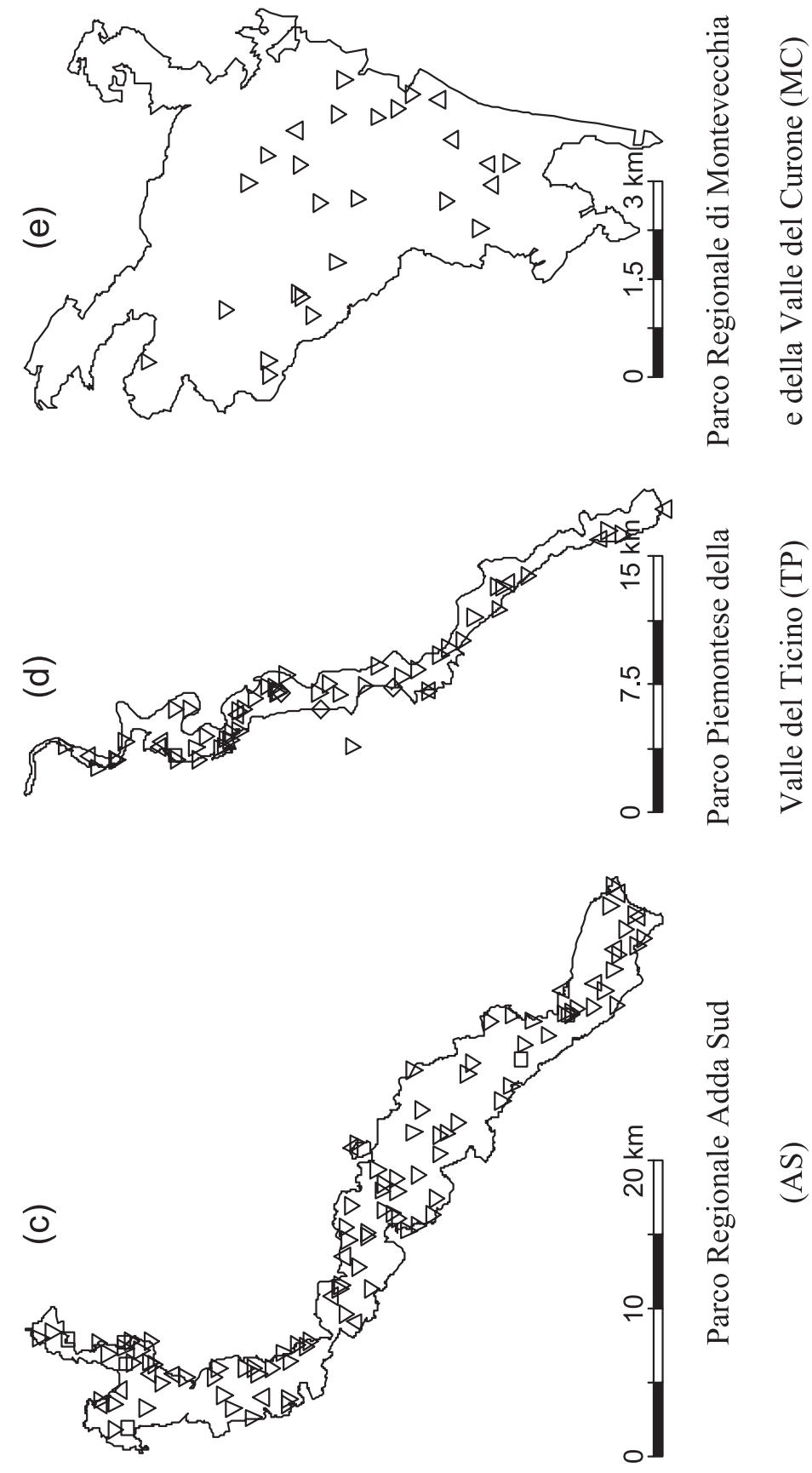

Figure 1. (a) Lombardy (dark grey) and Piedmont (light grey) in Italy and Europe. (b) The study areas in Lombardy and Piedmont: TP: Parco Piemontese della Valle del Ticino, MC: Parco Regionale di Montevecchia e della Valle del Curone, AS: Parco Regionale Adda Sud. (c-e) The monitored farms within each study area. Symbols represent the demographic trend of colonies between 2001 and 2010; squares: farms with constant demographic trend, upper triangles: farms with increasing populations; lower triangles: farms with decreasing populations; diamonds: farms where only presence-absence data were available. 
presence or absence of livestock on a farm in a given year. In addition, for each farm a three-level categorical variable ('livestock category') was generated, accounting for the presence of livestock in a farm both in 2001 and 2010 ('Present'), in none of the two years ('Absent'), or only in 2001 ('Ceased'). Three farms in AS and three in TP where livestock was reared in 2010 but not in 2001 were discarded from the analyses where this latter variable was entered as predictor.

\section{Statistical analyses}

The total population size at each study area in 2001 and 2010 was calculated by multiplying the mean colony size at each farm by the total number of farms at each study area. Standard errors of total population sizes were calculated while accounting for the sampling fraction (Sutherland 2006).

The annual growth rate of populations ( $r$ parameter) at each study area and at each farm was estimated as the slope of the Poisson regression, corrected for data overdispersion, of the number of breeding pairs on year (Pannekoek and van Strien 2005). The annual colony extinction probability (hereafter termed $E$ parameter) was calculated as above by regressing the number of colonies on year. Since most populations declined during the study period, in this paper we also refer to the 'decline rate' of a population as the opposite of the annual growth rate $(-r)$ for simplicity.

Estimates of $E$ from the sample of AS farms monitored in 2001 and 2010 were within the $95 \%$ confidence limits of the same parameters calculated on the AS farms sampled each year during 1999-2010 ( $E=0.011,95 \%$ CL: 0.005; 0.017; see Table 1 for estimates for 2001 and 2010). The value of $r$ estimated from farms monitored in 2001 and 2010 was slightly lower than that estimated from farms monitored each year during 1999-2010 ( $r=-0.063,95 \%$ CL: -0.092, -0.034). There was also no evidence of significant deviation from linearity of demographic trends estimated from Poisson regressions of annual censuses (significance of the quadratic term of year: $|t|_{9} \leq 1.0, P \geq 0.34$ in both cases). Hence, the analysis of data from 2001 and 2010 returned estimates of decline rates and extinction risk of colonies similar to those obtained by annual censuses. We therefore focused on parameter estimates obtained by the comparison of data collected in 2001 and 2010, as these data were available for all the study areas.

Decline rates were then compared among study areas and livestock categories in Generalized Linear Models (GLM) models or in Generalized Least Squares (GLS) models when variances were heterogeneous between study areas or cattle categories (Zuur et al. 2009). Colony extinction was coded as a dichotomous variable equal to $I$ if a colony that existed in 2001 was extinct in 2010 and to o otherwise. This variable was then analysed in binomial GLMs to investigate whether the probability of colony extinction differed between study areas and cattle categories. Post-hoc tests (Tukey method) were also performed. We note that the calculation of decline rates of populations allows us to easily compare demographic trends calculated in all years in 1999-2010 and in years 2001 and 2010.

Table 1. Summary statistics of demographic trends recorded in the different study areas; $n$ is the number of censused farms; $E$ is the annual extinction probability, $r$ is the annual population growth rate. Numbers in brackets represent standard errors. Estimates of total population sizes were obtained by the ratio estimator, and their standard errors were corrected for small populations.

\begin{tabular}{|c|c|c|c|c|c|c|c|c|c|}
\hline \multirow[t]{2}{*}{ Study area } & \multirow[t]{2}{*}{$n$} & \multicolumn{3}{|c|}{ number of colonies } & \multicolumn{3}{|c|}{$\begin{array}{l}\text { mean number of breeding } \\
\text { pairs per farm (SE) }\end{array}$} & \multicolumn{2}{|c|}{$\begin{array}{l}\text { estimated total } \\
\text { population size (SE) }\end{array}$} \\
\hline & & 2001 & 2010 & E & 2001 & 2010 & $r$ & 2001 & 2010 \\
\hline AS & 108 & 83 & 73 & 0.014 & 10.95 (1.33) & $4.76(0.66)$ & -0.093 & 3493 (117) & $1518(58)$ \\
\hline TP & 56 & 37 & 29 & 0.027 & $7.57(1.45)^{*}$ & $3.89(0.79)^{*}$ & -0.074 & $575(42)$ & $296(23)$ \\
\hline $\mathrm{MC}$ & 26 & 18 & 9 & 0.077 & $2.08(0.46)$ & $1.85(0.64)$ & -0.013 & 166 (10) & $148(14)$ \\
\hline
\end{tabular}

${ }^{*} n=53$ farms 
In order to investigate in detail the effect of livestock farming on the number of breeding Barn Swallow pairs per farm, and the effect of change in livestock farming on population trends and extinction probability, we used Generalized Linear Mixed Models (GLMMs). A Poisson error distribution was assumed in the models of number of breeding swallows at farms, a binomial error distribution in models of colony extinction and a Gaussian error distribution in models of population trend.

Year (2001 or 2010, entered as a dichotomous variable) was included as a fixed effect in the GLMMs of the number of breeding pairs at each study area. In developing these models, we first investigated the most appropriate structure of their random part. According to Zuur et al. (2009), we initially included year as a random slope at the farm level, and checked whether this improved the fit of the model. In all cases, random slope models fitted the data better than models only including farm as a random factor (likelihood ratio tests (LRT): $\chi^{2}{ }_{2} \geq 12.3, P \leq 0.002$ ). Inclusion of year as a random slope at the farm level allows the models to control for the between-farm variation in growth rates, and avoids inflating type-I error rate (Schielzeth and Forstmeier 2009). However, inclusion of random slopes enlarges the number of random parameters that must be estimated by the models. In our GLMMs, in particular, the number of random parameters was twice the number of farms (one intercept and one slope per farm), thus equalling the total number of available observations (two years of data per farm). Hence, the inclusion of a random slope in a model where only two years of data were available per farm saturated the number of random effects that could be entered in the model, as it is not possible to estimate a number of random effects larger than the number of observations. This prevented extension of the GLMM to analyse the effect of livestock farming on colony size at all study areas simultaneously. Indeed, a model of this kind would have required entering study area as an additional random factor. To obtain an overall test of the effect of livestock farming and year on the number of breeding pairs at all study areas, we therefore had to rely on a different approach, whereby we summarised the results from models for each study area by the weighted Z-method, a procedure that allows combining information across multiple tests of the same null hypothesis (Whitlock 2005).

Conversely, we used GLMMs with study area entered as a random factor and assuming a Gaussian or a binomial error distribution, to investigate the effect of livestock category on population trend or colony extinction probability, respectively, at all study areas. Since 'livestock category' seemed to differently affect decline rates and extinction probabilities in different study areas, we first included in the GLMMs this factor as a random slope within study area, besides as a fixed effect (Schielzeth and Forstmeier 2009). However in all cases, models with a simpler random structure only, including the study area as a random factor, had a similar fit than random slope models (LRTs: $\chi_{5}^{2} \leq 4.51, P \geq 0.48$ ), and were therefore preferred. Since models were underdispersed (dispersion parameter $\leq 0.70$ ), we conservatively did not correct for overdispersion in the Poisson and binomial GLMMs (Zuur et al. 2009).

We used R 2.8.1 (R Development Core Team 2008) for statistical analyses, with the nlme procedure (Pinheiro et al. 2008) for GLS and Gaussian mixed models, the lme4 procedure (Bates et al. 2008) for Poisson and binomial GLMMs, and the multcomp procedure (Bretz et al. 2001) for post-hoc tests.

\section{Results}

\section{Demographic trends in the three study areas}

Decline rates and extinction probabilities calculated for the three study areas by comparing the number of breeding pairs and the number of colonies recorded in 2001 and 2010 are shown in Table 1 . Combining the data from the three study areas it appeared that the size of the breeding population declined by $53.1 \%$ (i.e. by $8.4 \%$ per year), and the number of colonies by $19.6 \%$, between 2001 and 2010.

The decline rate of the breeding pairs in colonies that existed both in 2001 and 2010 significantly differed between study areas (GLS model for inequality of variances: $F_{2,104}=3.15, P<0.001$ ), 
with a significant difference between $\mathrm{AS}$ and $\mathrm{MC}$, while decline rates in the other comparisons were similar (Figure 2a; details not shown).

Study area also significantly explained variation in the probability of colony extinction (binomial GLM: $\chi_{2}^{2}=10.7, P=0.005$ ), that was significantly higher in MC than in AS. No other significant difference was observed (Figure $2 b$ ).

\section{Livestock farming and colony size and presence}

The mean number of breeding pairs per farm was significantly larger in farms with than without livestock, both in AS and TP, but not in MC (Table 2). The decline in the number of breeding pairs,
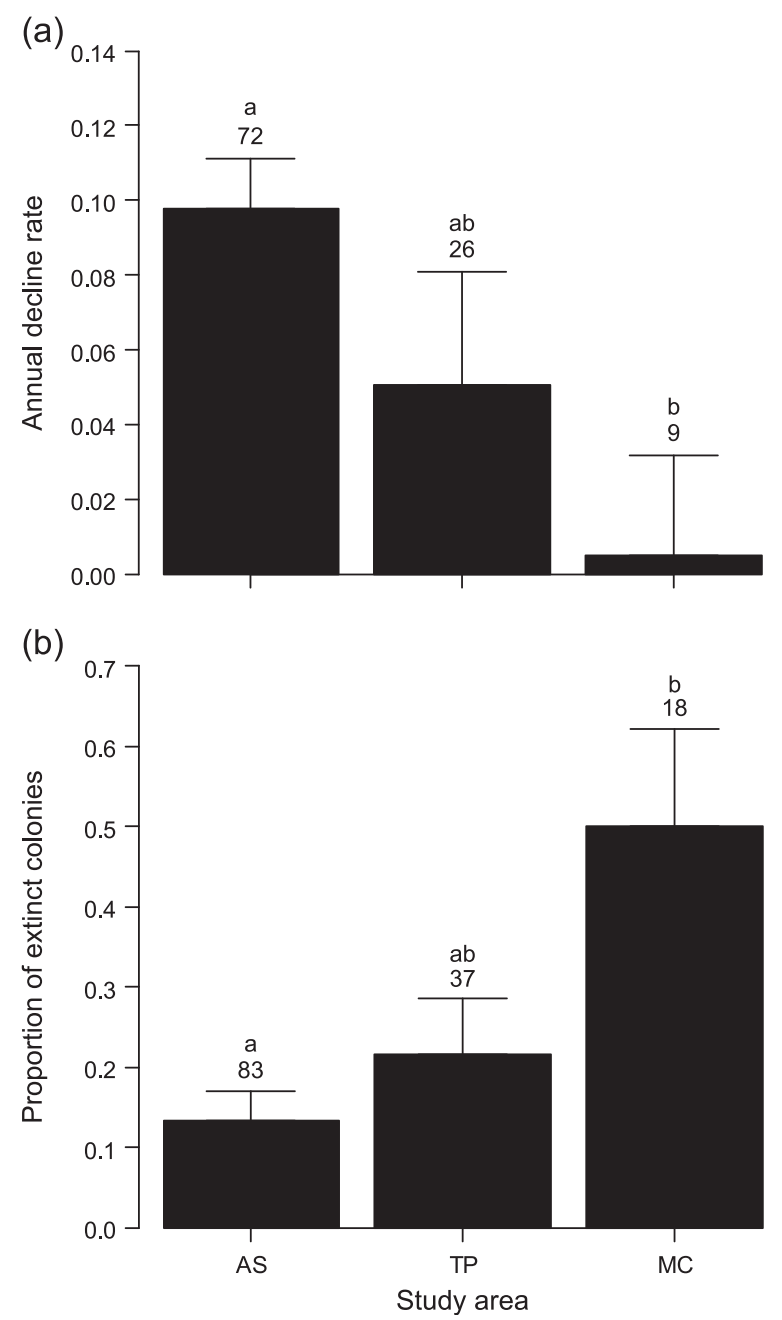

Figure 2. (a) Average annual decline rates ( $-r$ parameters in a population growth model) of Barn Swallow colonies and (b) proportion of colonies that went extinct between 2001 and 2010 in the Parco Regionale Adda Sud (AS), Parco Piemontese della Valle del Ticino (TP), Parco Regionale di Montevecchia e della Valle del Curone (MC). Bars represent standard errors. Numbers represent sample sizes. Bars with different letters indicate significant $(P<0.05)$ differences between study areas at post-hoc tests. 
that was statistically significant in all study areas (Table 2), occurred at a similar rate in farms with and without livestock, as indicated by the fact that the livestock by year interaction was never significant and was therefore removed from all models (AS: $-0.43 \pm 0.32 \mathrm{SE}, z=1.33, P=0.185$; TP: $0.57 \pm 0.51, z=1.1, P=0.27$; MC: $0.61 \pm 0.77 \mathrm{SE}, z=0.80, P=0.43)$. These findings were confirmed by pooling results from the three study areas (effect of livestock: $Z_{w}=-8.700$, $P<$ 0.001; effect of census year: $Z_{w}=-7.928, P<$ 0.001).

\section{Livestock farming and demographic trends}

Comparison of the decline rates of colonies on the farms censused both in 2001 and 2010 showed significant differences according to livestock category in TP $\left(F_{2,21}=6.70, P=0.006\right)$, with colonies on farms where livestock farming ceased declining more than those in the other livestock categories (post-hoc test: $|t|_{21} \geq 2.84, P \leq 0.025$, Figure 3a). Marginally non-significant differences were found in $\operatorname{AS}\left(F_{2,67}=2.79, P=0.068\right)$, and MC (GLS model for inequality of variances: $\left.F_{2,6}=4.93, P=0.054\right)$.

The mixed model analysis combining data from the three study areas revealed a significant variation in the decline rates according to livestock category $\left(F_{2,98}=6.90, P=0.001\right)$. Specifically, Barn Swallow colonies in farms where livestock farming ceased were estimated to decline significantly more than in farms where livestock was always or never reared $(|z| \geq 3.29, P \leq 0.003$; Figure 4a).

Probability of colony extinction varied according to livestock category in AS (LRT: $\chi_{2}^{2}=14.8$, $P<0.001$ ) and in TP (LRT: $\chi_{2}^{2}=7.9, P=0.020$, Figure 3 b), being significantly smaller in farms where livestock was reared in both years than in farms where livestock was always absent $(|z| \geq 2.40, P \leq 0.043)$. No significant difference in the probability of colony extinction between farms in different livestock categories appeared in MC (LRT: $\chi_{2}^{2}=1.9, P=0.383$ ).

The mixed model analysis of data from the three study areas revealed a highly significant difference in colony extinction probability between farms in different livestock categories (LRT: $\chi_{2}^{2}=25.1, P<0.001$ ), with colonies on farms where livestock was reared in both years showing a significantly smaller estimated extinction probability than that on farms where livestock was never reared and where it ceased between 2001 and 2010 (Figure 4 b). The difference in the probability of colony extinction between farms where livestock farming ceased and where livestock has never been reared was marginally non-significant (post-hoc test: $z=-1.85$, $P=0.064$ ). Addition of colony size in 2001 as a covariate did not affect the results (LRT of

Table 2. Fixed effects from Poisson GLMMs of the number of breeding pairs per farm according to presence of livestock farming and census year. The livestock per year interaction was never significant (all $P \geq 0.185$ ), and was therefore removed from the models. In all models farm was entered as a random factor and year as a by-farm random slope.

\begin{tabular}{|c|c|c|c|c|}
\hline Effect & Coef. & SE & $z$ & $P$ \\
\hline \multicolumn{5}{|c|}{ Parco Regionale Adda Sud } \\
\hline Livestock & 1.676 & 0.253 & 6.62 & $<0.001$ \\
\hline Year & -0.889 & 0.125 & -7.09 & $<0.001$ \\
\hline Intercept & -0.476 & 0.289 & -1.64 & 0.100 \\
\hline Livestock & 2.613 & 0.334 & 7.83 & $<0.001$ \\
\hline Year & -0.551 & 0.226 & -2.44 & 0.015 \\
\hline \multicolumn{5}{|c|}{ Parco Regionale di Montevecchia e della Valle del Curone } \\
\hline
\end{tabular}



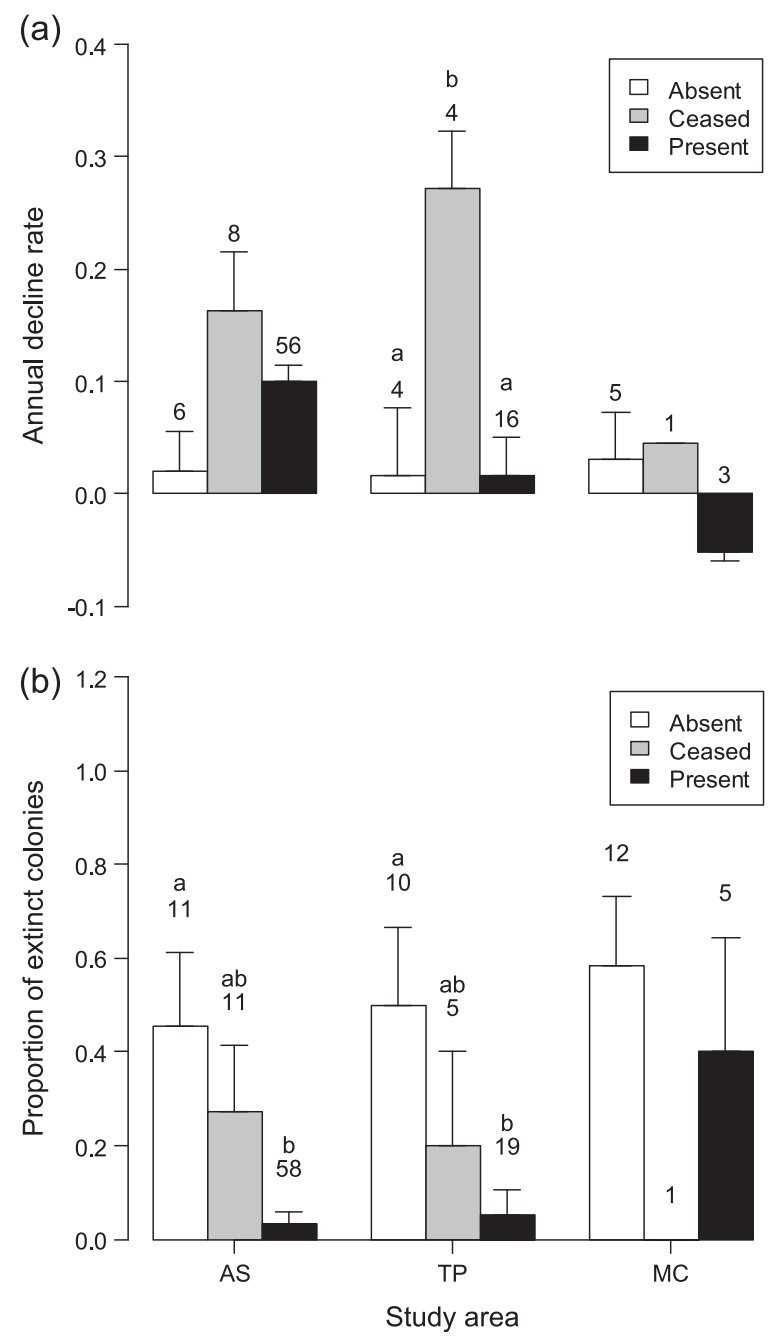

Figure 3. (a) Annual decline rates (-r parameter in a population growth model) of Barn Swallow colonies and (b) proportion of colonies that went extinct between 2001 and 2010 in the three livestock categories within each study area. Bars represent standard errors and numbers sample sizes. Bars with different letters indicate significant $(P<0.05)$ differences between the livestock categories within each study area at post-hoc tests.

livestock category: $\left.\chi_{2}^{2}=15.8, P<0.001\right)$ and revealed that initially large colonies had a smaller extinction probability compared to small ones (coefficient: $-0.170 \pm 0.058$ SE; LRT: $\chi^{2}{ }_{1}={ }_{15}$.1 $P<0.001)$. No interaction effect between livestock category and colony size in 2001 was observed (LRT of interaction: $\chi_{2}^{2}=4.29, P=0.12$ ).

\section{Discussion}

In this study we gathered current (2010) and historical (2001) information on the size of breeding Barn Swallow populations in a very large sample of 190 farms in three study areas in Northern Italy where general ecological conditions differ. We also collected detailed information on colony 

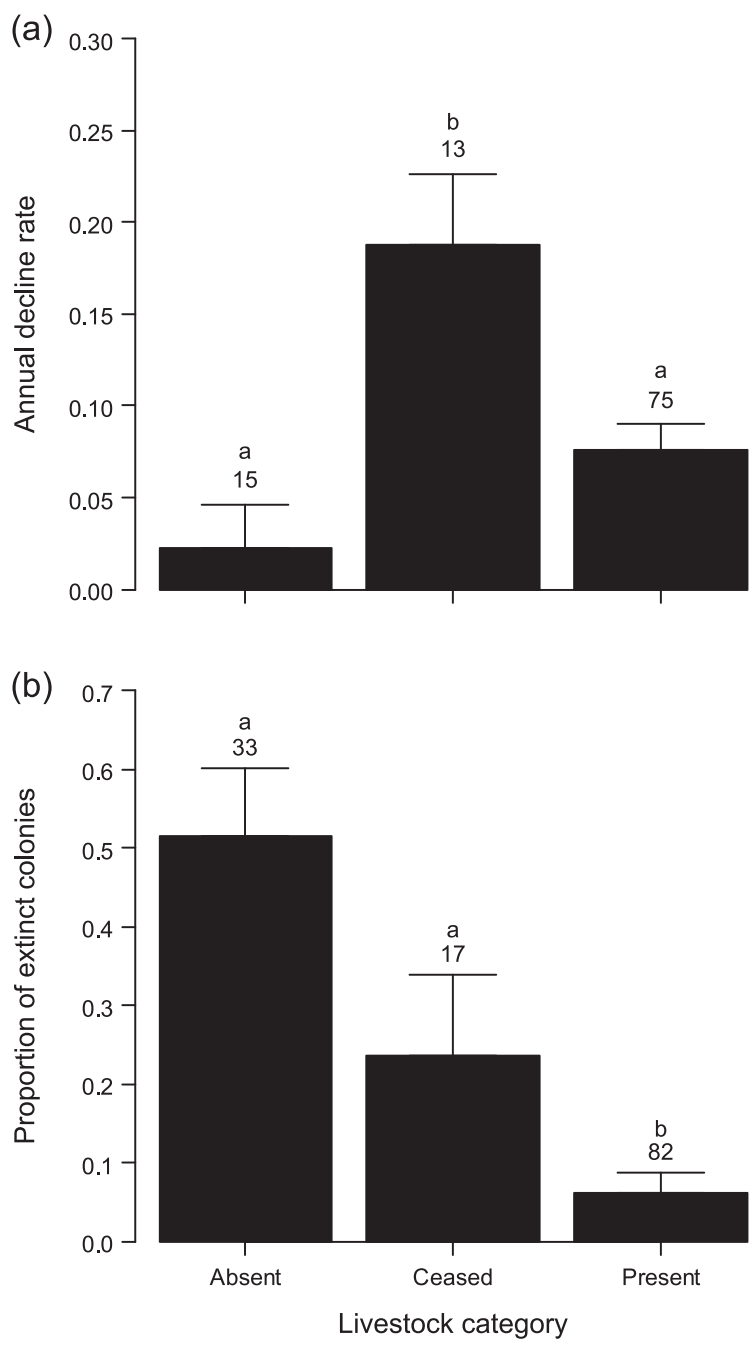

Figure 4. (a) Annual decline rates (-r parameter in a population growth model) of Barn Swallow colonies and (b) proportion of colonies that went extinct between 2001 and 2010 in farms in different cattle categories in the three study areas. Bars represent standard errors and numbers sample sizes. Bars with different letters indicate significant $(P<0.05)$ differences between cattle categories at post-hoc tests.

size in each year between 1999 and 2010 in 94 farms in one study area, and we could therefore assess that demographic trends calculated on the basis of data from 2001 and 2010 reliably reflect those from annual censuses.

We documented a dramatic decline in the Barn Swallow population ( $8.4 \%$ per year), larger than that reported for the whole of Lombardy (4.3\% per year) by Bani et al. (2009) by means of point counts, and much larger than the $9 \%$ estimated for Europe by the European Bird Census Council in the period 1990-2006, corresponding to an annual decline of $1 \%$ (EBCC 2008, PECBMS 2009). This decline is however similar to that documented in a Danish population during 1970-1999 ( $7.6 \%$ per year), for which time to extinction was estimated at 22 years by means of stochastic population models (Engen et al. 2001). Differences in demographic trends among Barn Swallow 
populations breeding in different parts of Europe are probably due to differences in farming practices (and in their change over time) among European regions (Báldi and Batáry 2011). In addition, geographical populations of Barn Swallow segregate in different African regions during winter (Ambrosini et al. 2009, 2011), and therefore may be affected differently by changes in ecological conditions at their wintering grounds.

Barn Swallow populations are known to show large fluctuations at decadal scales (Siriwardena et al. 1998, Robinson et al. 2003). However, the decline of this population seems almost continuous during the 1o study years, at least in AS, as indicated by the fact that overall population trend in the sample of farms that were monitored in all years did not deviate from linearity (see Methods). In addition, the observed decline seems, unfortunately, to reflect the steep negative demographic trend of this species in the Po plain that took place in previous years. Indeed, Selmi and Checchi (2001) reported a decline of 54.6\% in the number of Barn Swallow pairs breeding in the municipality of Spilamberto (Modena province) between 1990 and 1999. This information therefore suggests that Barn Swallows in Northern Italy may have declined to one quarter of their initial population size during the last 20 years.

Barn Swallows seem to have declined at different rates in the three study areas. Before further discussing these results, two main caveats deserve consideration. First, the number of farms that were censused both in 2001 and 2010 was much lower in MC than in the other study areas. The non-significant results in the analysis comparing population size and trend at farms in different cattle categories in MC may therefore be due to the low power of statistical tests. Second, sampling protocols in 2001 (but not in 2010) differed among study areas, as farms in TP and MC were visited monthly in that year, while farms in AS every second week. We checked whether different sampling rates may have biased our estimates of colony sizes in 2001 and, consequently, of decline rates. To this end, we reassessed the number of breeding pairs at 20 randomly chosen farms in AS in 2001 as if we had sampled them once a month, rather than every second week. This was simply done by considering only the data collected on each second visit to a farm. Halving the sampling rate implied a reduction of estimated decline rate at a colony by only 0.005 , i.e. one order of magnitude lower than the significant difference in decline rates between AS and MC (0.09 $\pm 0.03 \mathrm{SE}$, Figure 2). Hence, we are confident that difference in sampling rates in different areas did not bias our general conclusions.

The decline was steeper in AS, an intensively cultivated area in the low Po plain where mean colony size was the largest, and lowest in MC, a hilly area that hosted the smallest colonies, being intermediate in TP, an intensively cultivated area in the high Po plain, where mean colony size is also intermediate. Intensification of farming practices, which have been invoked to explain negative trends of Barn Swallow populations in Switzerland (Grüebler et al. 2010), may have occurred at different rates in the three study areas, and may therefore explain the observed differences in decline rates. Indeed, AS and TP, where swallows declined the most, are more intensively cultivated than MC. However, colony extinctions have occurred at a lower rate in AS and in TP than in MC, probably due to the larger average size of colonies in the former study areas. In addition, in MC half of the colonies went extinct between 2001 and 2010, probably because several farms were remodelled in these years (R. Ambrosini, pers. obs.), and therefore have probably become unsuitable for Barn Swallow reproduction. MC may therefore be an area where Barn Swallows breed at low densities due to reduced breeding site availability. Farms are smaller in this study area compared to the others, and farm density is higher. In addition, climate and general ecological conditions in this hilly area differ from those in the other intensively cultivated study areas on the plain. Habitats in MC may therefore be sub-optimal for this species, as suggested by the observation that in 2010 farms in MC hosted an average number of breeding pairs (1.18 $\pm 0.37 \mathrm{SE})$ similar to that of farms without livestock in the other study areas (AS: 1.70 \pm 0.43 ; TP: $0.82 \pm 0.34)$.

Presence of livestock farming at a farm positively influenced the size of Barn Swallow colonies, as expected (e.g. Møller 1994, 2001, Ambrosini et al. 2002, Turner 2006), in AS and TP, and in the analyses combining the results at the three study areas, but not in MC. This lack of association 
between livestock farming and Barn Swallow distribution at this area is difficult to explain, and may again be related to the different general ecological conditions in this area. Alternatively, it may simply be the by-product of the low power of statistical tests due to the small sample of farms at this study area.

The strong positive association between Barn Swallows and livestock explains the large negative impact that cessation of livestock farming had on their breeding populations. Indeed, colonies in the farms where livestock farming ceased declined more steeply than those in farms where livestock was always or never reared. This result is consistent with previous studies carried out in Denmark (Møller 2001), which demonstrated that cessation of livestock farming determined a lower recruitment of yearlings, leading to a rapid decline of the colony (Møller 2001). In addition, presence of livestock in the same room of the nest favours Barn Swallow reproduction (Ambrosini et al. 2006, Ambrosini and Saino 2010, Grüebler et al. 2010). However, the number of farms with livestock declined by approximately 10\% between 2001 and 2010 in all three study areas (AS: $10.8 \%$. TP: $9.09 \%$, MC: $10.0 \%$ ), so the observed variation in the decline rate of populations between these areas could not be explained by differential variation in farming practices.

Probability of colony extinction also differed among livestock categories, being largest in farms that never hosted livestock, intermediate in farms where livestock farming ceased, and smallest in farms always with livestock. In our sample, farms where livestock farming ceased between 2001 and 2010 hosted a similar number of breeding pairs in 2001 than farms where it was maintained (as assessed by a Poisson mixed model with study area as a random factor: $z=1.75, P=0.08$ ). The intermediate extinction probability in farms where livestock farming ceased may therefore result from a steeper decline of originally large colonies.

Presence of livestock seems therefore to enhance the number of pairs breeding at a farm, probably by a combination of direct and indirect benefits to Barn Swallow reproduction. First, flying insects are more abundant in farms with than without livestock (Møller 2001). Second, hayfields, which are the preferred foraging sites for Barn Swallows (Ambrosini et al. 2002, Evans et al. 2007), are wider around farms with livestock (+11.6\% in 2010, our unpubl. data) within $400 \mathrm{~m}$ of the farm, corresponding to the foraging range of this species (Ambrosini et al. 2002). Third, rooms housing livestock are significantly warmer than rooms without, and this affects nestling phenotype (Ambrosini et al. 2006, Ambrosini and Saino 2010) and survival (Grüebler and Naef-Daenzer 2006). All these benefits disappear after cessation of livestock farming, probably resulting in the steep decline in colony size we observed. In addition, buildings housing livestock are usually accessible to Barn Swallows for nesting, but, once farming ceases, may be rearranged and become inaccessible to swallows, thus determining nest site loss. Unfortunately, we have no detailed information on accessibility of buildings to breeding Barn Swallows in 2001 both in TP and MC. Conversely, in AS we could estimate the impact of nest site loss on breeding colonies. The rate of decline of colonies in farms where buildings that hosted breeding swallows in 2001 were remodelled or made otherwise unavailable for the swallows in 2010 ( $n=54$ farms), was not larger than that in farms where all nest sites were preserved $\left(n=16\right.$ farms) ( $t$-test: $t_{68}=1.00$, $P=0.32)$. The effect of nest site reduction was also not significant when the effect of cattle category was taken into account (GLM: $\mathrm{F}_{1,66}=0.14, \mathrm{P}=0.71$, other details not shown). Hence, nest site loss does not seem to have determined the decline of colonies in AS. However, the effect of nest site loss may have been more severe in TP and MC than in AS, as average farm size is much lower in the first two areas than in the latter (see Methods). Remodelling of buildings in a manner that denied access may therefore have contributed to the general decline of Barn Swallows in these areas.

Small colonies have also become extinct with a higher probability than large ones. These originally small colonies probably occurred in sub-optimal areas where recruitment of young individuals in their first breeding season was probably low, and became even smaller in a period of general population decline.

Three farms in AS and three in TP started livestock farming between 2001 and 2010. Colonies in two of these farms went extinct, while the other showed slightly positive demographic trends 
$(r=+0.02 \pm 0.04$ SE on average, $n=4)$. The extinct colonies were very small in 2001 (one and two breeding pairs, respectively), and, at least in one case, extinction is probably the result of disturbance due to farm rearrangement (albeit the old cowshed was maintained at this farm). The positive trend in the other farms thus supports the hypothesis that livestock farming enhances the suitability of a farm to Barn Swallow reproduction, albeit the small sample size prevented formal statistical analyses.

Barn Swallow breeding colonies have declined at a similar rate in farms where livestock farming has either never been practised or where cattle occurred in all years. This suggests that the general decline of breeding populations is due not only to cessation of livestock farming, but also to other causes. Changes in general climatic conditions both in the breeding and the wintering grounds may be involved, as they seem to have determined a severe decline in the populations of several migratory birds (Møller et al. 2008). In addition, changes in environmental conditions both in the wintering grounds and along migration routes have been shown to affect survival of migrant birds (Szép et al. 2006), mainly for those species inhabiting dry open habitats during winter (Sanderson et al. 2006). This may have profound effects on population size of several species, as adult mortality of aerial insectivores like the Barn Swallow mainly occurs during these phases of the annual life cycle (Robinson et al. 2008).

\section{Conservation implications}

The Barn Swallow is currently listed as "Least Concern" by IUCN (2010), but the sharp decline we documented (about 50\% in 1o years) calls for planning conservation strategies for this species in Italy and elsewhere (e.g. Denmark; Engen et al. 2001). The general negative trend observed in all three study areas, irrespective of changes in livestock farming practices, is probably due to factors acting over larger or even global geographical scales, such as climatic and environmental changes in the African wintering and passage areas, as is likely for many other African wintering species (Sanderson et al. 2006, Møller et al. 2008, Both et al. 2009, Jones and Cresswell 2010, Saino et al. 2011). However, changes in farming practices occurring in the breeding quarters, such as the cessation of livestock farming, appear to have additive negative effects on Barn Swallow populations. Conservation actions aiming at buffering the global negative trends of Barn Swallows should thus favour the maintenance of livestock farming, which appears pivotal in limiting the decline of the breeding populations of this species. Whether the buffering effect of livestock farming on Barn Swallow declines is due to livestock presence per se, possibly via its positive effects on seasonal reproductive success (Grüebler et al. 2010), or to habitat characteristics associated with livestock farming, such as pastures and hayfields, that represent preferential foraging sites for the species, remains to be elucidated. Agri-environment schemes (AES) specifically designed for Barn Swallow conservation should focus on the maintenance of livestock farming at farms, as swallow colonies were largest, declined the least, and had the lowest extinction risk on farms that always had livestock. However, to the best of our knowledge, we are unaware of any AES specifically designed for Barn Swallow conservation. Nevertheless, this species may benefit from implementation of AES aimed at maintaining hayfields and improving hedgerows, as these habitats are preferred foraging sites (Ambrosini et al. 2002, Evans et al. 2007, Grüebler et al. 2010). A less intensive approach to farming and a more wildlife-friendly agriculture, which should be promoted by the future Common Agricultural Policy, may be beneficial for farmland birds in general (Báldi and Batáry 2011) and, hopefully, also for the Barn Swallow. However, the benefit of an environmentally friendly approach to agriculture for Barn Swallow is not unequivocal, as this species was found to be more abundant in organic than in traditional farms in Denmark (Christensen et al. 1996), but not in the Netherlands (Kragten and de Snoo 2008, Kragten et al. 2009). In addition, Barn Swallows population levels were not correlated with agricultural intensification in Britain (Robinson et al. 2003).

At a local scale, conservation actions would be most effective in AS than in other study areas, both because the population decline was steepest in this area, and because it still supports the 
largest population. Unfortunately, AES specifically designed for improving Barn Swallow populations seem difficult to plan in this area, as they would imply large economic costs to farmers. Indeed, cessation of livestock farming and conversion of hayfields to arable fields for biomass production is currently economically advantageous to farmers (R. Ambrosini, unpubl. data).

In conclusion, our study suggests a careful assessment of the conservation status of the migratory Barn Swallow that has showed an alarming local population decline, and indicates that plans for Barn Swallow conservation should aim to maintain livestock farming, as this may contribute to limiting population declines.

\section{Acknowledgements}

We are grateful to all the farm owners who allowed us to carry out this study in their cowsheds and houses. The GEV group of the Parco Regionale di Montevecchia e della Valle del Curone kindly provided data from 2001 and also contributed to field work in 2010. Several field assistants greatly contributed to data collection in all years. We thank the Parco Regionale Adda Sud, the Parco Piemontese della Valle del Ticino and the Parco Regionale di Montevecchia e della Valle del Curone for logistic support. The study was carried out under the auspices of the "Programma di cooperazione transfrontaliera Italia-Svizzera 2007-2013 - Indagine naturalistica e variabilità ambientale" (INTERREG project ID 157624065 - Misura 1.2) and was partly funded by the Università degli Studi di Milano (grant 2009-ATE-oo15 to D.R.) and the Parco Regionale Adda Sud.

\section{References}

Ambrosini, R. and Saino, N. (2010) Environmental effects at two nested spatial scales on habitat choice and breeding performance of barn swallow. Evol. Ecol. 24: 491-508.

Ambrosini, R., Bolzern, A. M., Canova, L., Arieni, S., Møller, A. P. and Saino, N. (2002) The distribution and colony size of barn swallows in relation to agricultural land use. J. Appl. Ecol. 39: 524-534.

Ambrosini, R., Ferrari, R. P., Martinelli, R., Romano, M. and Saino, N. (2006) Seasonal, meteorological, and microhabitat effects on breeding success and offspring phenotype in the barn swallow, Hirundo rustica. Ecoscience 13: 298-307.

Ambrosini, R., Møller, A. P. and Saino, N. (2009) A quantitative measure of migratory connectivity. J. Theor. Biol. 257: 203-211.

Ambrosini, R., Saino, N., Rubolini, D. and Møller, A. P. (2011) Higher degree-days at the time of breeding predict size of second clutches in the barn swallow. Clim. Res. 50: 43-50.

Báldi, A. and Batáry, P. (2011) The past and future of farmland birds in Hungary. Bird Study 58: 365-377.
Bani, L., Massimino, D., Orioli, V., Bottoni, L. and Massa, R. (2009) Assessment of population trends of common breeding birds in Lombardy, Northern Italy, 1992-2007. Ethol. Ecol. Evol. 21: 27-44.

Bates, D., Maechler, M. and Dai, B. (2008) lme4: Linear mixed-effects models using $S_{4}$ classes. R package version 0.999375-28. http://lme4.r-forge.r-project.org/

BirdLife International (2004) Birds in Europe: Population estimates, trends and conservation status. Cambridge, UK: BirdLife International.

Both, C. and Visser, M. E. (2001) Adjustment to climate change is constrained by arrival date in a long-distance migrant bird. $\mathrm{Na}$ ture 411: 296-298.

Both, C., Bouwhuis, S., Lessells, C. M. and Visser, M. E. (2006) Climate change and population declines in a long-distance migratory bird. Nature 441: 81-83.

Both, C., van Turnhout, C. A. M., Bijlsma, R. G., Siepel, H., Van Strien, A. J. and Foppen, R. P. B. (2010) Avian population consequences of climate change are most severe for long-distance migrants in 
seasonal habitats. Proc. R. Soc. B 277: 1259-1266.

Both, C., van Asch, M., Bijlsma, R. G., van den Burg, A. B. and Visser, M. E. (2009) Climate change and unequal phenological changes across four trophic levels: constraints or adaptations? J. Anim. Ecol. 78 : $73-83$.

Bretz, F., Genz, A. and Horton, L. A. (2001) On the numerical availability of multiple comparison procedures. Biometrical J. 43: 645-656.

Chamberlain, D. E. and Fuller, R. J. (2001) Contrasting patterns of change in the distribution and abundance of farmland birds in relation to farming system in lowland Britain. Glob. Ecol. Biogeogr. 10: 399-409.

Chamberlain, D. E., Fuller, R. J., Bunce, R. G. H., Duckworth, J. C. and Shrubb, M. (200o) Changes in the abundance of farmland birds in relation to the timing of agricultural intensification in England and Wales. J. Appl. Ecol. 37: 771-788.

Christensen, K. D., Jacobsen, E. M. and Nøhr, H. (1996) A comparative study of bird faunas in conventionally and organically farmed areas. Dansk Orn. Foren. Tidsskr. 90: $21-28$.

Cramp, J. (1988) Handbook of the birds of Europe, the Middle East and North Africa. The birds of the Western Palearctic. Vol. V. Oxford, UK: Oxford University Press.

Donald, P. F., Green, R. E. and Heath, M. F. (2001) Agricultural intensification and the collapse of Europe's farmland bird populations. Proc. R. Soc. B 268: 25-29.

Donald, P. F., Sanderson, F. J., Burfield, I. J. and van Bommel, F. P. J. (2006) Further evidence of continent-wide impacts of agricultural intensification on European farmland birds, 1990-2000. Agricult. Ecosyst. Environ. 116: 189-196.

EBCC (2008) Trends of common birds in Europe, 2008 update. European Bird Census Council. Available at: http://www.ebcc. info/index.php? ID $=358$, .

Engen, S., Sæther, B. and Møller, A. P. (2001) Stochastic population dynamics and time to extinction of a declining population of barn swallows. J. Anim. Ecol. 70: 789-797.

Evans, K. L., Wilson, J. D. and Bradbury, R. D. (2007) Effects of crop type and aerial in- vertebrate abundance on foraging barn swallows Hirundo rustica. Agricult. Ecosyst. Environ. 122: 267-273.

Grüebler, M. U. and Naef-Daenzer, B. (2006) The duration of post-fledging parental care in the Barn Swallow: Relevance to fitness. J. Ornithol. 147: 78.

Grüebler, M. U., Korner-Nievergelt, F. and von Hirschheydt, J. (2010) The reproductive benefits of livestock farming in barn swallows Hirundo rustica: quality of nest site or foraging habitat? J. Appl. Ecol. 47: 1340-1347.

IUCN (2010) 2010 IUCN Red List of threatened species. Version 2010.4. <www.iucn redlist.org $>$. Downloaded on 14 February 2011.

Jones, T. and Cresswell, W. (2010) The phenology mismatch hypothesis: are declines of migrant birds linked to uneven global climate change? J. Anim. Ecol. 79: 98108.

Kragten, S. and de Snoo, G. R. (2008) Fieldbreeding birds on organic and conventional arable farms in the Netherlands. Agric. Ecosyst. Environ. 126: 270-274.

Kragten, S., Reinstra, E. and Gertenaar, E. (2009) Breeding Barn Swallows Hirundo rustica on organic and conventional arable farms in the Netherlands. J. Ornithol. 150: 515-518.

Møller, A. P. (1989) Population dynamics of a declining swallow Hirundo rustica L. population. J. Anim. Ecol. 58: 10511063.

Møller, A. P. (1994) Sexual selection and the Barn Swallow. Oxford, UK: Oxford University Press.

Møller, A. P. (2001) The effect of dairy farming on barn swallow Hirundo rustica abundance, distribution and reproduction. J. Appl. Ecol. 38: 378-389.

Møller, A. P., Rubolini, D. and Lehikoinen, E. (2008) Populations of migratory bird species that did not show a phenological response to climate change are declining. Proc. Natl. Acad. Sci. USA 105: 1619516200.

Pannekoek, J. and van Strien, A. (2005) TRIM 3 Manual (Trends and indices for monitoring data). The Hague, The Netherlands: Statistics Netherlands. 
PECBMS (2009) The state of Europe's common birds 2008. Prague, Czech Republic, CSO/RSPB.

Pinheiro, J., Bates, D., DebRoy, S., Sarkar, D. and the R Core team (2008) nlme: Linear and nonlinear mixed effects models. $\mathrm{R}$ package version 3.1-89.

$\mathrm{R}$ Development Core Team (2008) R: $A$ Language and Environment for Statistical Computing. Vienna, Austria: R Foundation for Statistical Computing.

Robinson, R. A., Balmer, D. E. and Marchant, J. H. (2008) Survival rates of hirundines in relation to British and African rainfall. Ring. Migr. 24: 1-6.

Robinson, R. A., Crick, H. Q. P. and Peach, W. (2003) Population trends of Swallows Hirundo rustica breeding in Britain. Bird Study 50: 1-7.

Saino, N., Ambrosini, R., Rubolini, D., von Hardenberg, J., Provenzale, A., Hüppop, K., Hüppop, O., Lehikoinen, A., Lehikoinen, E., Rainio, K., Romano, M. and Sokolov, L. (2011) Climate warming, ecological mismatch at arrival and population decline in migratory birds. Proc. R. Soc. B 278: 835-842.

Saino, N., Szép, T., Ambrosini, R., Romano, M. and Møller, A. (2004) Ecological conditions during winter affect sexual selection and breeding in a migratory bird. Proc. $R$. Soc. B 271: 681-686.

Sanderson, F. J., Donald, P. F., Pain, D. J., Burfield, I. J. and van Bommel, F. P. J. (2006) Long-term population declines in Afro-Palearctic migrant birds. Biol. Conserv. 131: 93-105.

Schielzeth, H. and Forstmeier, W. (2009) Conclusions beyond support: overconfident estimates in mixed models. Behav. Ecol. 20 : 416-420.

Selmi, E. and Checchi, L. (2001) Nidificazione delle rondine Hirundo rustica presso Spilamberto (Modena). Avocetta 25: 68.

Siriwardena, G. M., Baille, S. R., Buckland, S. T., Fewster, R. M., Marchant, J. H. and Wilson, J. D. (1998) Trends in abundance of farmland birds: a quantitative comparison of smoothed Common Bird Census indices. J. Appl. Ecol. 35: 24-43.

Sutherland, W. J. (2006) Ecological census techniques. Second Edition. Cambridge, UK: Cambridge University Press.

Szép, T., Møller, A. P., Piper, S., Nuttall, R., Szabo, Z. D. and Pap, P. L. (2006) Searching for potential wintering and migration areas of a Danish Barn Swallow population in South Africa by correlating NDVI with survival estimates. J. Ornithol. 147: 245-253.

Tucker, G. M. and Heath, M. F. (1994) Birds in Europe: Their conservation status. Cambridge, UK: Birdlife International.

Turner, A. (2006) The Barn Swallow. London, UK: T \& A D Poyser.

Whitlock, M. C. (2005) Combining probability from independent tests: the weighted Z-method is superior to Fischer's approach. J. Evol. Biol. 18: 1368-1373.

Zuur, A. F., Ieno, E. I., Walker, N. J., Saveliev, A. A. and Smith, G. M. (2009) Mixed effects models and extensions in ecology with R. New York, NY: Springer.

Zwarts, L., Bijlsma, R. G., van der Kamp, J. and Wymenga, E. (2009) Living on the edge. Wetlands and birds in a changing Sahel. Zeist, The Netherlands: KNNV Publishing.

ROBERTO AMBROSINI*, BEATRICE SICURELLA

Dipartimento di Biotecnologie e Bioscienze, Università degli Studi di Milano Bicocca, Piazza della Scienza, 2 I-20126 Milano, Italy.

DIEGO RUBOLINI, ANDREA ROMANO, CHIARA SCANDOLARA, MARIA ROMANO, NICOLA SAINO

Dipartimento di Biologia, Università degli Studi di Milano, Via Celoria, 26, I-20133 Milano, Italy. 
PAOLA TROVÒ, GIOVANNI LIBERINI, MARCO BANDINI

Ente di gestione delle aree protette del Ticino e del Lago Maggiore, Villa Picchetta, I-28062 Cameri (NO), Italy.

*Author for correspondence; email: roberto.ambrosini@unimib.it

Received 4 April 2011; revision accepted 4 November 2011;

Published online 19 July 2012 